\title{
Françoise Revaz, Introduction à la narratologie. Action et narration
}

Jean François Plamondon

\section{(2) OpenEdition}

10 Journals

\section{Édition électronique}

URL : http://journals.openedition.org/studifrancesi/6449

DOI : ERREUR PDO dans /localdata/www-bin/Core/Core/Db/Db.class.php L.34 : SQLSTATE[HY000]

[2006] MySQL server has gone away

ISSN : 2427-5856

\section{Éditeur}

Rosenberg \& Sellier

Édition imprimée

Date de publication : 1 novembre 2010

Pagination : 595

ISSN : 0039-2944

\section{Référence électronique}

Jean François Plamondon, «Françoise Revaz, Introduction à la narratologie. Action et narration », Studi Francesi [En ligne], 162 (LIV | III) | 2010, mis en ligne le 30 novembre 2015, consulté le 07 janvier 2021 URL : http://journals.openedition.org/studifrancesi/6449; DOI : https://doi.org/ERREUR PDO dans / localdata/www-bin/Core/Core/Db/Db.class.php L.34 : SQLSTATE[HY000] [2006] MySQL server has gone away

Ce document a été généré automatiquement le 7 janvier 2021.

\section{(c)}

Studi Francesi è distribuita con Licenza Creative Commons Attribuzione - Non commerciale - Non opere derivate 4.0 Internazionale. 


\title{
Françoise Revaz, Introduction à la narratologie. Action et narration
}

\author{
Jean François Plamondon
}

\section{RÉFÉRENCE}

FRANÇOISE REVAZ, Introduction à la narratologie. Action et narration, Bruxelles, De Boeck/

Duculot, 2009, pp. 224.

1 Professeure à l'Université de Fribourg en Suisse, Françoise Revaz propose un manuel utile à tous ceux qui veulent se (re)mettre à jour dans le domaine des études narratologiques. Suivant un double programme, sémantique de l'action et narratologique, l'auteure retourne aux textes philosophiques fondamentaux que sont ceux de Paul Ricœur et réactualise la théorie narratologique en fonction des nouvelles tendances du discours. Extrêmement bien documenté, l'ouvrage revient d'abord sur les théories de l'action rappelant que si l'action appartient à la volonté et à l'intentionnalité humaine, l'événement, quant à lui, travaille dans une contingence que l'homme n'a toujours pas appris à dompter ni à prévoir. Les aléas de la nature, souvent plus forts que l'homme, imposent toujours leurs règles quand ils décident d'intervenir dans le destin des individus. Or, malgré le fait que l'homme et la science ont atteint le troisième millénaire, le discours, qui tente d'expliquer les intempéries ou les événements naturels, fait toujours intervenir des modulations verbales qui portent à croire que si Darwin a véritablement gagné son pari contre les explications divines, l'homme continue de penser que derrière les événements naturels se cache une forme d'intentionnalité. Revaz démontre que nous continuons de nous émerveiller devant le spectacle d'une éclipse à tel point que nous en sommes à applaudir devant le malaise que crée en nous une telle manifestation naturelle. Si cela peut paraître éloigné de la narratologie, il faut y voir plutôt une représentation de ce que Ricœur appelle la préfiguration, qui serait un mode commun de précomprendre le monde lorsque l'on aborde la lecture d'un récit. Et s'il y a une forme de récit qui appelle de tout son être la préfiguration, c'est bien le récit pictural. En effet, comment comprendre un Caravaggio 
sans partager avec lui une base de la vision du monde? Revaz écrit: «Le peintre peut postuler des connaissances chez l'interprète» (p. 91). Ce qui est vrai pour le monde de l'art pictural n'est pas faux pour l'art du récit littéraire. C'est d'ailleurs à la formulation d'une définition du récit que Revaz s'applique. Si elle en vient à dire qu'il n'y a pas de définition universelle et acceptée par tous les chercheurs, «le récit est considéré tantôt comme un mode d'énonciation, un agencement de faits, une structure textuelle, un acte de parole, voire le résultat d'une stratégie de lecture» (p. 100), Françoise Revaz relève toutefois un nombre de propriétés sémantiques communes: «Une représentation d'actions, un déroulement chronologique, une transformation entre l'état initial et l'état final, un enchaînement causal, un développement inhabituel ou non prévisible de l'action» (p. 100).

2 Après avoir passé en revue des approches québécoise, française, étasunienne, allemande, après s'être arrêtée sur les catégories textuelles de la narrativité, Revaz propose enfin de reconnaître sous le vocable «récit» des textes qui présenteraient un critère spécifique: celui d'une «mise en intrigue, c'est-à-dire un mode de composition spécifique comprenant un NEUD et un DÉNOUEMENT» (p. 124). Revaz se place ici dans le courant classique suivant la Poétique d'Aristote, Les principes de la littérature de l'abbé Charles Batteux ou les Temps et récit de Paul Ricœur. Opposé à la chronique et à la relation, le récit obtient «le plus haut degré de narrativité. Lui seul, en effet, manifeste une structure d'intrigue, c'est-à-dire un mode de composition comportant un nœud et un dénouement» (p.137). Or il semble que le nœud et le dénouement dans la littérature postmoderne ne portent pas nécessairement la marque de l'action, mais s'articulent plutôt dans la toile du hasard, un hasard recréé certes, mais vécu comme tel par les personnages. C'est du moins ce que démontre Revaz en parcourant l'œuvre de JeanPhilippe Toussaint. Dans les livres de cet auteur belge, «la construction romanesque n'obéit pas à une logique de déroulement où les événements adviendraient les uns en conséquence des autres. Seul le hasard semble présider à la destinée des personnages» (p. 166). Personnages bien souvent restés à l'état de fonction tant ils demeurent dans l'indétermination. L'étude de Revaz se termine sur un type de récit original, dont la portée laisse songeur. Analysant le feuilleton médiatique comme s'il s'agissait d'une narration obéissant à des règles poétiques, elle en vient à démontrer que le traitement de l'information dans les journaux suit une logique comparable à celle d'un récit, tel qu'elle l'a défini plus haut. Basé sur une dynamique de l'incomplétude, le traitement de l'information journalistique suit ni plus ni moins la règle qui a fait tenir Schéhérazade pendant plus de mille nuits. Arrivé à la fin de l'essai de Revaz, on en vient à se demander si le traitement de la fiction et ses modulations narratives ne sont pas tributaires des modulations discursives qui traitent du réel dans les quotidiens. Ce qui nous ramène à postuler que les frontières entre le réel et la fiction doivent véritablement se dessiner hors du champ propre de la narratologie et imposer leur espace dans des pratiques lectorales qui discriminent l'un et l'autre des univers de mots. 